\title{
Design and Implementation of a Wall Climbing Robot
}

\author{
Riad Hossain Faisal \\ American International University of Bangladesh \\ Kemal Ataturk Avenue, \\ Banani, Dhaka, Bangladesh
}

\author{
Nafiz Ahmed Chisty \\ American International University of Bangladesh \\ Kemal Ataturk Avenue, \\ Banani, Dhaka, Bangladesh
}

\begin{abstract}
It has been a long time that scientists are trying to move vehicles both in the vertical and horizontal plane simultaneously by the same machine. Working against gravity made it difficult to roll the wheels in a surface that is very steeply inclined to the ground plane. This paper work deals with the design and implementation of a wireless controlled motor vehicle with the ability to move in both vertical and horizontal plane. Aerodynamic techniques have been used to hold the vehicle in any inclined vertical plane. The paper work covers both electrical and mechanical portions. The mechanical portion has been designed using Solid works and 3D studio MAX while the electrical parts has been designed and simulated using Proteus VSM tool.
\end{abstract}

\section{General Terms}

Surveillance, Space activities, Fire rescue operation, Security activities

\section{Keywords}

Wall climber, Robot, Aerodynamic, Wireless communication

\section{INTRODUCTION}

Robot is one of the most important and revolutionary inventions of modern science. It is a kind of electro mechanical machine which can perform various tasks automatically according to the installed programmable commands. Robots can perform different tasks in an unfriendly environment where it is tough for human to accomplish it. In the modern scientific era, robots are one of the most exclusive inventions by which our life became easier and comfortable. Climbing robots are mainly adopted in places where direct access by a human operator is very expensive, because of the need for scaffolding, or very dangerous, due to the presence of a hostile environment. In the last decades, different applications have been envisioned for wall climber robots, mainly in the technical inspection, maintenance, surveillance, space activities and failure or breakdown diagnosis in dangerous environments. These tasks are necessary in the outside of tall buildings, bridges, nuclear power plants or pipelines, for scanning external surfaces of gas or oil tanks and offshore platforms, for performing nondestructive tests in industrial structures, and also in planes and ships. Furthermore, they have been applied in civil construction repair and maintenance, in the prevention and fire-fighting actions, in anti-terrorist actions, in cleaning operations in sky-scrapers, for cleaning the walls and ceilings of restaurants, for transportation of loads inside buildings and for reconnaissance in urban environments.Finally, their application has also been proposed in the education and human care areas. [1]

\section{HISTORICAL BACKGROUND}

A lot of research has been done with wall climbing robots and various types of experimental models have been already proposed. Different types of wall climbing robots are made based on different mechanism like legged mechanisms, sliding mechanisms and tracked wheel mechanisms. Legged mechanism is used to build such robots that can overcome uneven surfaces. Due to their heavy weight and complicated control system, these results in low speed and discontinuous motion. Meanwhile, the sliding mechanism is relatively simple in comparison with legged mechanisms, but the problem remains with discontinuous motion. In searching to the solution of this problem, many research has been devoted on Tracked wheel mechanism for faster and continuous motion [2]. In recent years, several different approaches have been taken to develop robots that have the ability to climb vertical surfaces against the gravitational force like, Wallbots, Stickybots etc. Wallbots used magnetic force to run on the vertical planes. The Stanford Research Institute (Also known as, SRI Technology) creates Shakey the first mobile robot to know and react to its own actions [3]. A research group of Dr. Li Hiu has recently successfully developed the bionic robot; which are also called gecko robots, named "Speedy Freelander". This gecko robot can instantly climb up and down in a variety of building walls, walking upside down on the ceiling or, ground and vertical wall fissure [4]. In 2007, Researchers at the Robotics Institute at Carnegie Mellon University (CMU) have created a robot that can run up a wall as smooth as glass and onto the ceiling at a rate of six centimeters a second which uses fibers that are twice as adhesive as those used by geckos [5]. At the 2008 IEEE International Conference on Robotics and Automation (ICRA 2008), engineers presented their wall climbing bot which inspired from geckos. The robot could scale buildings or creep up windows, secretly spying for hours. They could also be used for search-andrescue operations. More benignly, they could inspect and repair the hard-to-reach parts of airplanes, spacecraft, and bridges [6]. In collaboration between Disney Research Zurich and ETH, a wall climbing robot named VertiGo was built. The robot has two tiltable propellers that provide thrust onto the wall, and four wheels. One pair of wheels is steerable, and each propeller has two degrees of freedom for adjusting the direction of thrust. By transitioning from the ground to a wall and back again, VertiGo extends the ability of robots to travel through urban and indoor environments [7]. Hao Yangand Rong Liu proposed in this paper the vibration suction 
method(VSM) which is a another kind of suction strategy for wall climbing robots [8]. Stephen Paul Linder have designed a low cost robot to climb in inclined surface using computer vision [9].The paper by Jason $\mathrm{Gu}$ proposed a research on wall climbing robot with permanent magnetic tracks where mechanical system architecture is also described in the paper [10]. Shanging Wu proposed wireless distributed wall climbing robotic system for reconnaissance purpose [11]. Design and control of a lightweight magnetic climbing robot for vessel inspection by Markus Eich and Thomas Vogele is proposed for the solution for inspection of marine vessels [12]. Houxiang Zhangs paper presented three different kinds of robots for cleaning the curtain walls of high structural building [13].

\section{METHODOLOGY}

The idea and primary knowledge of the robot was gathered from different research and journal papers. Primarily a list of different components had been made. A theoretical research was done on the electric and electronic components. Torque, speed, pressure and power of different components were calculated theoretically. A prototype body of the robot was designed using 3D Studio MAX and Auto CAD 3D. Then solid works simulation was used for calculating the required strain, stresses, friction and balance. Difference between simulation result and theoretical calculation was thoroughly observed and the correction was made. As a consequence, the main body of the robot was again designed which reduced the size and weight of the body compared to theprototype design. The project work had been divided into two major parts: mechanical and electrical.

\subsection{Mechanical Part}

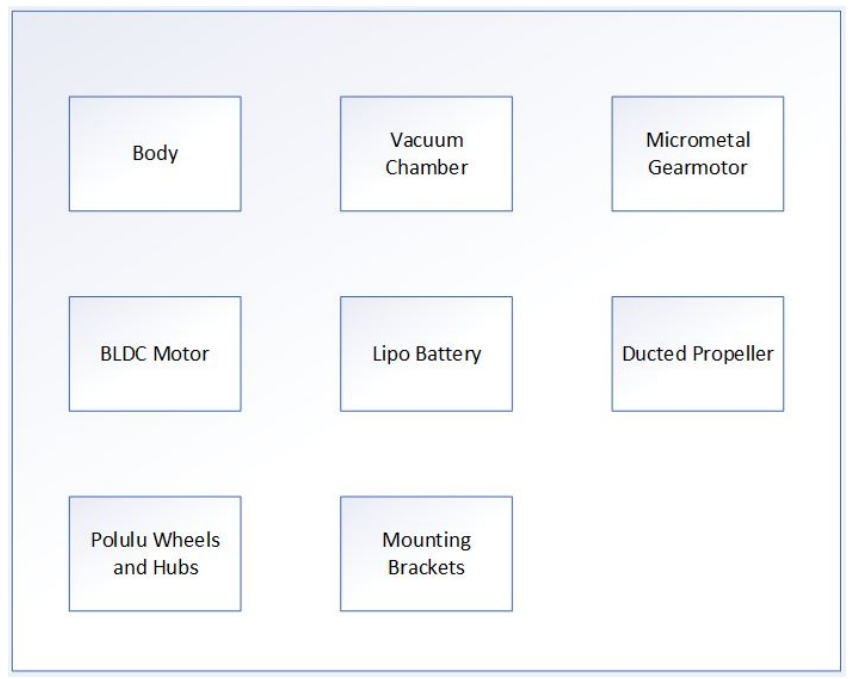

Fig. 1. Block representation of the mechanical portion of the work.

Mechanical portion of the robot is constructed based on aerodynamic technology which is showing in Fig. 1. A vacuum chamber is created in the middle of the body where an electrical suction cup is placed to stick the robot on any inclined surface. The diameter of the vacuum chamber is $8 \mathrm{~cm}$. Total basement size is 108 inches. Suction mechanism where a RF transmitter receiver is used to control the speed of BLDC motor is illustrated in Fig. 4. Ducted impeller with high speed BLDC motor inside the suction cup flows the air to the outside direction of the vacuum chamber. Thus air pressure inside the vacuum chamber becomes low compared to atmospheric pressure. This high atmospheric pressure exerts force on the robot to the direction of the wall to stick it on the wall. Fig. 4 shows the arrangement for controlling the speed of the BLDC motor. A $2800 \mathrm{KV}$ BLDC motor with $45 \mathrm{~A}$ ESC powered by 4 cell Lithium Polymer battery is used to control the speed of the motor according to required adhesion. Ducted propeller which is set to BLDC motor was made of strong light plastic. Its diameter was 7 $\mathrm{cm}$. Four micrometal gearmotor HP with gear ratio 210:1 has been used to move the robot against the adhesion on vertical plane. One single motor can create torque up to $3.6 \mathrm{~kg} / \mathrm{cm}$. Polulu $4219 \mathrm{~mm}$ wheel was used in the robot. These wheels were used for greater friction and durability. Another reason to use these wheels was to fit the output shafts of the micrometal gear motor. Fig. 2 illustrates the whole setup, how the connection is made and how the robot moves on both horizontal and vertical plane.

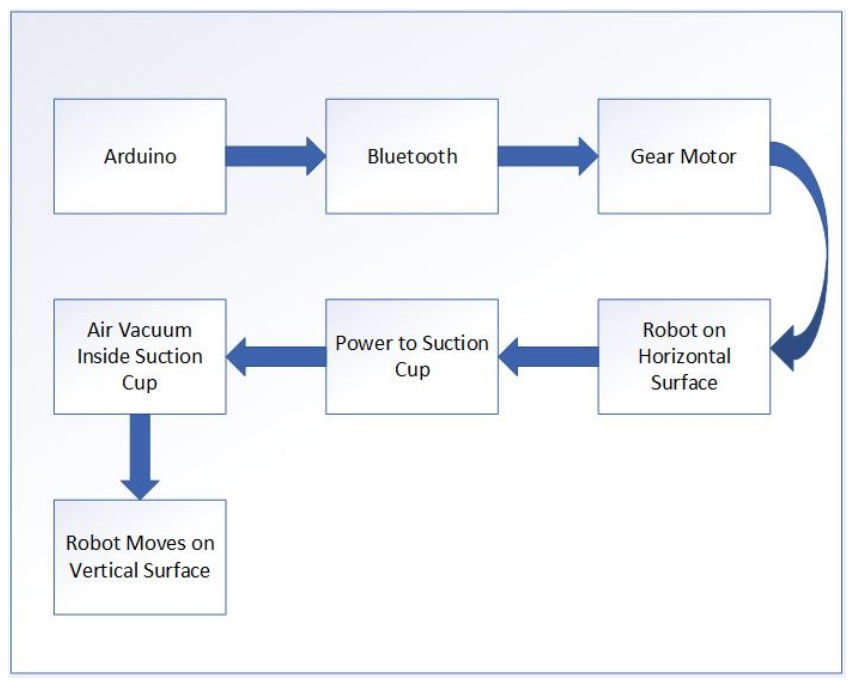

Fig. 2. Flowchart of the wall climbing robot.

\subsection{Electrical Part}

Electrical part of the robot is based on microcontroller and wireless technology. An android application name ArduionoRC was used to send command from the android device to the bluetooth module. ZS-040 Bluetooth module has been used to receive the command from the android device. This is mainly a HC-05 Bluetooth to Serial Module (With ZS040 Baseplate) for arduino. Arduino connected with this module is able to establish a wireless bluetooth connection with pc or smartphone with built in bluetooth feature. The HC05 Module worked at 3.3V, but it was fitted on a baseboard that provides voltage regulation for input voltage ranging from $3.6 \mathrm{~V}$ to $6 \mathrm{~V}$. Arduino UNO R3 with ADAFRUIT motor shield was used to drive the micrometal gear motor according to the command. ADAFRUIT motor shield can drive up to 4 DC motors and 2 stepper motors. In this motor shield, TB6612 MOSFET driver was used instead of L293D with 1.2A per channel and 3A peak current capability which is the exact requirement for the gearmotor used in this project. Fig. 3 illustrates block representation of the electrical portion of the work. ArduionoRC allows the user to set a UUID of his own bluetooth module in order to connect the 


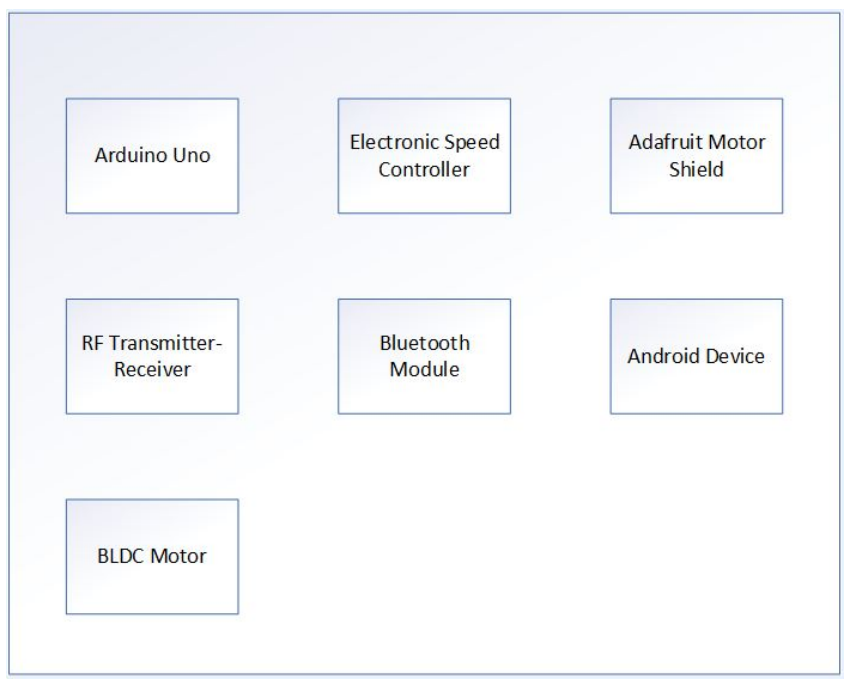

Fig. 3. Block representation of the electrical portion of the work.

android application with the project. This software contains 4 different command modes which enabled precise control of the robot in vertical plane. Fig. 5 and Fig. 6 shows control procedure of electrical components and speed control technique of BLDC motor respectively.

Mechanical Part:

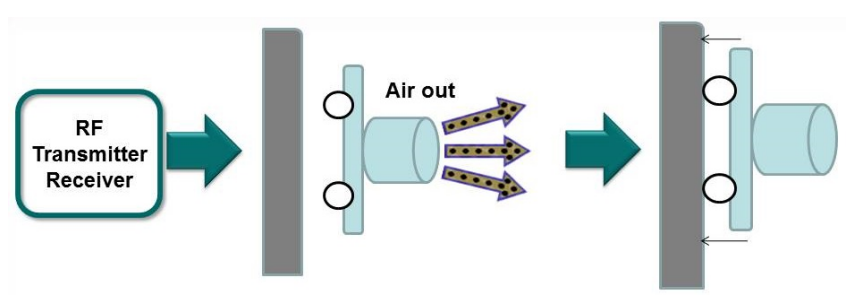

Fig. 4. Suction Mechanism.

Electrical Part:
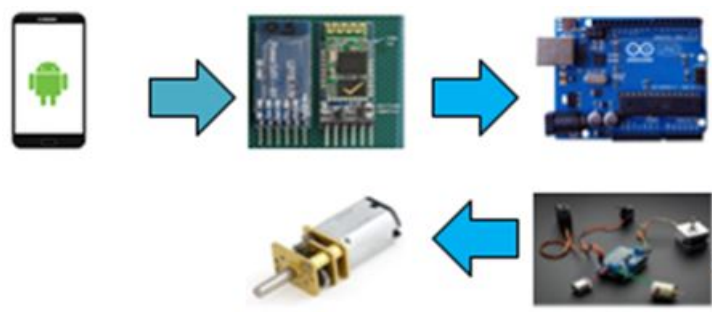

Fig. 5. Controlling electrical components.

\section{DESIGN AND SIMULATION}

Solid works and 3D studio MAX has been used for simulation and further improvement of the final design. Solid works simulation has been used for calculating the strain, stresses, pressure and friction of different components of the robot. Applied force, carrying loads,

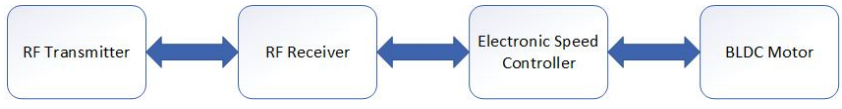

Fig. 6. Block diagram of speed controlling of BLDC motor.

pressure and torques are also calculated by using solid works simulation. Fig. 7 shows the initial design of the robot. Finally the body has been designed in a single part to reduce its weight and to make it faster. Fig. 8 shows the suction cup with ducted propeller. It is

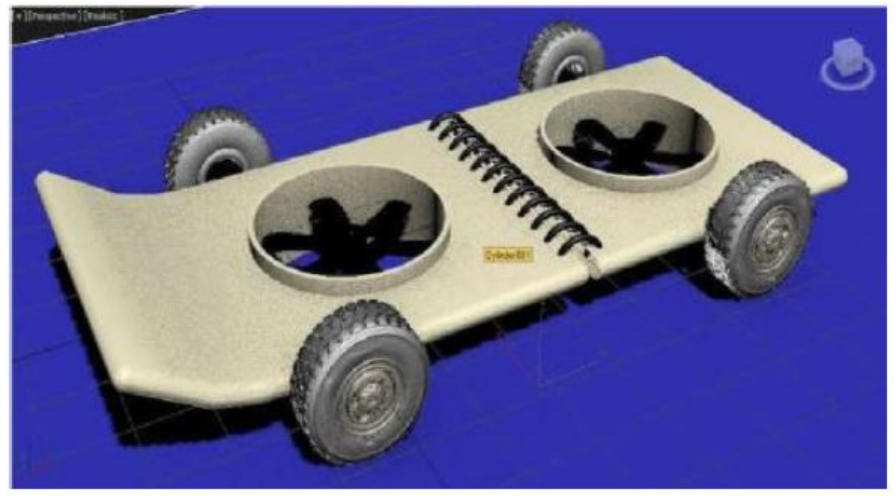

Fig. 7. Initial design of the robot.

made by strong but light plastic. The diameter of the basement is 8 $\mathrm{cm}$. Fig. 9 shows the extended portion of the suction cup which is

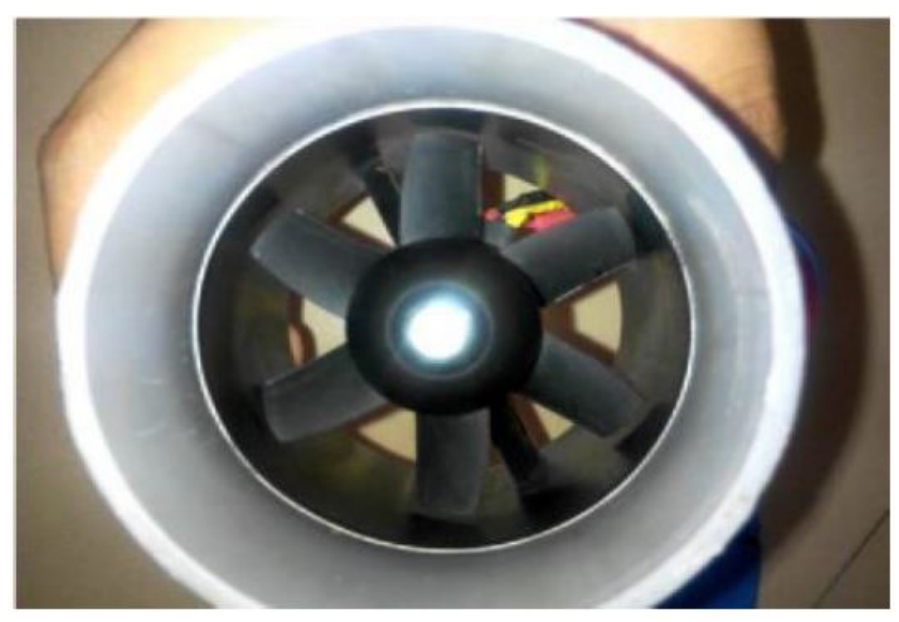

Fig. 8. Suction cup with ducted propeller.

extended by $2 \mathrm{~cm}$ keeping the basement unchanged.

Fig. 10 represents the circuit connections of Arduino Uno and ADAFRUIT motor shield with four motors. After getting signal from android application transmitter, Bluetooth module passes that signal to the receiver pin of Arduino. Bluetooth module is activated by connecting $+5 \mathrm{~V}$ dc supply to $\mathrm{Vcc}$ pin. The transmitter pin of Arduino transmits those signals to the ADAFRUIT motor shield. ADAFRUIT motor shield has 4 channel to run up to 4 DC motors, 


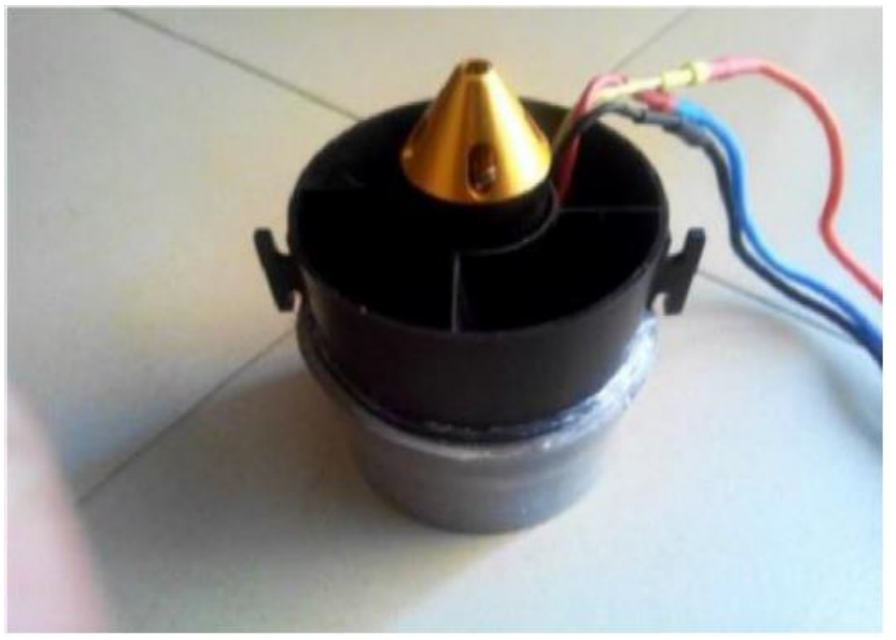

Fig. 9. Extended suction cup.

each channel can provide a maximum current of $1.2 \mathrm{~A}$ using the signal which are transmitted from the Bluetooth module to Arduino.

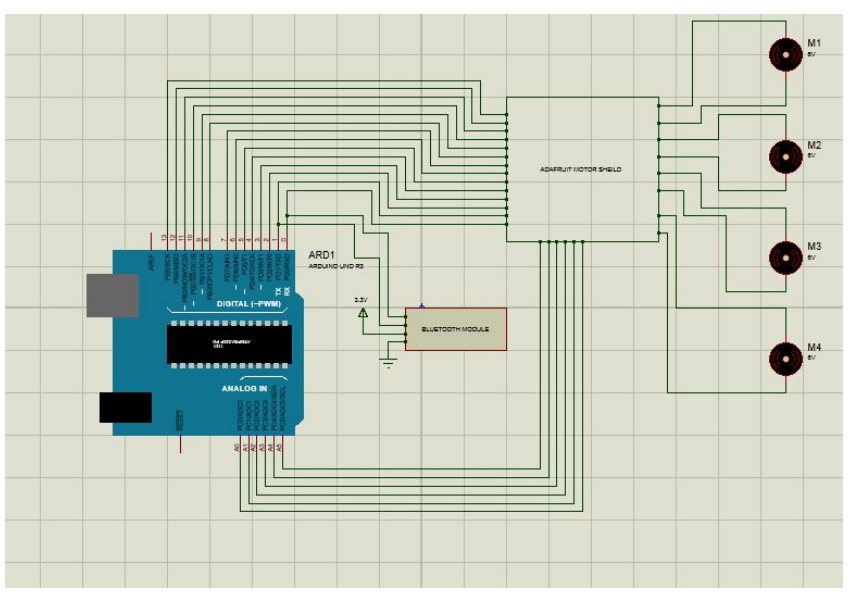

Fig. 10. Circuit simulation of Arduino Uno.

\section{COMPARISON}

This project was primarily focused on designing a cost effective wall climbing robot with greater efficiency compared to other wall climbing robots those are based on different technology and mechanism. Table 1 shows the different items used and specification of the robot with vacuum caterpillar wheel system operated climbing robot [14]. Table 2 illustrates cost comparison of both the wall climbing robots [15]-[20].

\section{CONCLUSION}

This Wall Climbing robot is mainly done by suction process which can be fruitful under air atmosphere, but places where air pressure is very low or no-air like outer space; secondary formula for gripping like magnetic or adhesive process can be introduced. This work had to gone through the trade of between making the vehicle
Table 1. Specification of aerodynamic and tracked wheel mechanism based robot.

\begin{tabular}{|c|c|c|}
\hline \multicolumn{3}{|c|}{ Specification } \\
\hline Differences & $\begin{array}{l}\text { Wall Climbing Robot } \\
\text { (Aerodynamic tech- } \\
\text { nology) }\end{array}$ & 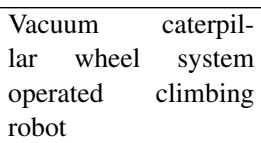 \\
\hline Dimension & $10 * 8$ inch & $\begin{array}{l}460 \mathrm{~mm} * 460 \mathrm{~mm} * 200 \\
\mathrm{~mm}\end{array}$ \\
\hline $\begin{array}{lr}\text { Weight } & \text { (including } \\
\text { vacuum } & \text { pump,power } \\
\text { supply) } & \end{array}$ & $650 \mathrm{gm}$ & Approx. $14 \mathrm{~kg}$ \\
\hline Max. climbing speed & $15 \mathrm{inch} / \mathrm{sec}$ & $9 \mathrm{inch} / \mathrm{sec}$ \\
\hline Driving motor & $\begin{array}{l}\text { Micrometal Gear Mo- } \\
\text { tor HP }\end{array}$ & $\begin{array}{l}\text { 1EA, Faulhaber } \\
\text { BLDC,200W (111:1) }\end{array}$ \\
\hline Power supply & $\begin{array}{lr}\text { Li-ion } & \text { polymer } \\
\text { battery(14.8 } & \mathrm{V} \text {, } \\
3000 \mathrm{mAh}) & \end{array}$ & $\begin{array}{l}\text { Li-ion polymer bat- } \\
\text { tery }(25.9 \mathrm{~V}, 11 \mathrm{Ah})\end{array}$ \\
\hline Vacuum pump & $\begin{array}{l}2800 \mathrm{KV} \text { BLDC mo- } \\
\text { tor,45A ESC.RPM } \\
41000 \mathrm{RPM} .\end{array}$ & $\begin{array}{l}\text { 1 EA, N838DC, KNF } \\
\text { Max flow rate } 32 \\
\mathrm{~L} / \mathrm{min} \text {. }\end{array}$ \\
\hline Vacuum Pressure & $1.2 \mathrm{~kg}$ & 100 mbar abs. \\
\hline
\end{tabular}

Table 2. Cost Comparison.

\begin{tabular}{|l|l|l|}
\hline \multicolumn{3}{|c|}{ Specification } \\
\hline Difference & $\begin{array}{l}\text { Wall Climbing Robot } \\
\text { (Aerodynamic tech- } \\
\text { nology) }\end{array}$ & $\begin{array}{l}\text { Vacuum caterpil- } \\
\text { lar wheel system } \\
\text { operated climbing } \\
\text { robot }\end{array}$ \\
\hline Driving Motor & 60.00 USD(4 pcs) & 85.20 USD \\
\hline Power & 45.50 USD & 50.00 USD \\
\hline Motor Diver & 15.00 USD & 20.00 USD \\
\hline Control System & 90.00 USD & 130.00 USD \\
\hline
\end{tabular}

strong and lighter at the same time; as making stronger the vehicle makes it bulky and heavier. Thus, the adjustment between vacuum chamber (suction cup) and the ducted fan had been made several times for making the robot lighter with a strong body. Currently the robot is using lower range Bluetooth technology for wireless communication, this made the range to control the vehicle very limited. It is possible to increase the range by using GPS or satellite and control the robot from long distances. It can be used in collecting information from distant places by adding camera, microphone and wireless transmitter to stream multimedia. An arm can be added to pick or collect objects too in the near future. An X-RAY scanner, a Night vision camcorder or a fire extinguisher could be added as well for some security activities and fire rescue operations. Artificial Intelligence can be added on it so that it can take some quick and instant decision by itself in various situations.

\section{REFERENCES}

[1] B. Vishanth, S. Kathiravan, S. Giri prasad, R. Raju and D. James deepak "Analysis of wall climbing robot", International Journal of Innovative Research in Science, Engineering and Technology, vol. 3, no. 3, pp. 1-2, 2014.

[2] H. Kim, D. Kim, H. Yang, K. Lee, K. Seo, D. Chang and J. Kim "Development of a wall-climbing robot using a tracked wheel mechanism", Journal of Mechanical Science and Technology, vol. 22, no. 8, pp. 1490-1498, 2008. 
[3] "A Brief History of Robotics, Historical Background". [Online]. Available: http://robotics.megagiant.com/history.htm. [Accessed: 02- Mar- 2015]

[4] "Daily News Report By Dr.Li Hiu Yeung, Bionic Gecko Robot". [Online]. http://www.rcmodelswiz.co.uk/electronicspeedcontrollersesc [Accessed: 07- Mar- 2015]

[5] "D. Graham-Rowe, "Wall-Climbing Robot", 2007”. [Online]. https://www.technologyreview.com/s/407767/wall-climbingrobot/ [Accessed: 07- Mar- 2015]

[6] "Wall-Climbing Robot Spies", IEEE Spectrum: Technology, Engineering, and Science News, 2008". [Online]. https://spectrum.ieee.org/robotics/roboticssoftware/wallclimbing-robot-spies [Accessed: 09- Mar2015]

[7] "VertiGo - A Wall-Climbing Robot including Ground-Wall Transition - Disney Research", Disney Research, 2015". [Online]. https:https://www.disneyresearch.com/publication/vertigo/ [Accessed: 03- Jan- 2016]

[8] H. Yang, R. Liu, Q. Hong and N. Shun Bu he "A Miniature Multi Joint Wall Wall - Climbing Robot Based On New Vibration Suction Robotic Foot", in IEEE International Conference On Automation And Logistics Qingdao, China, 2008, pp. 1160-1165

[9] S. Paul linder, E. Wei and A. Clay "Robotic Rock Climbing Using Computer Vision And Force Feedback", in IEEE International Conference On Robotics And Automation, Barcelona, Spain, 2005, pp. 46854690

[10] W. Shen, J. Gu and Y. Shen "Proposed Wall Climbing Robot With Permanent Magnetic Tracks For Inspecting Oil Tanks", in IEEE International Conference On Mechatroincs And Automation, Canada, 2005, pp. 20722077

[11] S. Wu, M. Li, S. Xiao and Y. Li "A Wireless Distributed Wall Climbing Robotic System For Reconnaissance Purpose", in IEEE international Conference On Mechatronics And Automation, 2006, pp. 1308-1312

[12] M. Eich and T. Vogele "Design And Control Of A Lightweight Magnetic Climbing Robot For Vessel Inspection", in IEEE 19th Mediterranean Conference On Control And Automation, Aquis Corfu Holiaday Palace, Corfu,Greece, 2011, pp. 12001205.

[13] H. Zhang, J. Zhang and G. Zong "Effective Pneumatic Scheme and Control Strategy of a Climbing Robot for Class Wall Cleaning on High-rise Buildings", International Journal of Advanced Robotic Systems, vol. 3, no. 2, p. 28, 2006.

[14] H. kim, D. Kim, H. Yang, K. Lee and J. Kim ”A wall climbing robot with vacuum caterpillar wheel system operated by mechanical valve”, in International Conference on Climbing and Walking Robots, Sep.2006., Brussels, Belgium, 2006.

[15] "Faulhaber BLDC motor". [Online]. https://www.indiamart.com/proddetail/faulhaber-dcmotorwith- encoder-6700289991.html [Accessed: 05Feb- 2016]

[16] "Li-ion [Online]. polymer battery $(25.9 \mathrm{~V}, 11 \mathrm{Ah}) "$. china.com/product/HBgnhdtonMcI/China-Qualified-18650Li-ion-25-9V-Lithium-Battery-11Ah-.html [Accessed: 05Feb- 2016]
[17] "Li-on polymer battery(14.8 V,300 mAh)". [Online]. https://hobbyking.com/en-us/batteries/zippybatteries/zippylipoly. html [Accessed: 15- Jan- 2016]

[18] "BLDC motor 2800KV ". [Online]. http://www.alibaba.com/product-detail/111 Vrc2800kvbrushlessmotor-60354766230.html?spm $=a 2700$. 7724838.0.0.JhIlZN [Accessed: 05- Feb- 2016]

[19] "Micro Metal Gearmotor HP". [Online]. https://www.pololu.com/product/996. [Accessed: 15- Jan2016]

[20] "Adafruit motor shield for Arduino UNO". [Online]. https://www.adafruit.com/products/81. [Accessed: 15- Jan2016] 